\title{
Collaborative Innovation in Smart Networks - a Methods Perspective
}

\author{
Armin Lau ${ }^{1}$, Thomas Fischer ${ }^{1}$, Sven-Volker Rehm ${ }^{1}$, Manuel Hirsch ${ }^{1}$ \\ ${ }^{1}$ German Institutes of Textile and Fiber Research Denkendorf - Centre for Management Research, \\ Koerschtalstrasse 26, 73770 Denkendorf, Germany, \\ \{armin.lau,thomas.fischer,sven.rehm,manuel.hirsch\}@ditf-denkendorf.de
}

\begin{abstract}
Innovation management methods have been subject to extensive research during the last decades, many of which have found their way to application in practice. However, innovation management methods are still predominantly used within company boundaries, although knowledge contributions of external business partners could often boost the benefits of applying these methods. Smart Networks, focusing on Organizational Networking, Knowledge Networking and Information and Communication Technology (ICT) Networking, offer an approach for the collaborative, inter-enterprise implementation of such methods. This paper presents an engineering approach for how innovation management methods can be applied collaboratively within this specific form of enterprise networking. An approach to implement innovation management methods with help of ICT applications is highlighted. Exemplarily, an implementation of the Failure Mode and Effects Analysis (FMEA) method is illustrated.
\end{abstract}

\section{Keywords}

Collaborative Innovation, Innovation Management, Methods for Innovation Management, Smart Networks

\section{Introduction}

The development of innovative products and processes is considered a key factor for keeping competitiveness in today's rapidly changing industrial environment. In order to innovate, knowledge from various sources is required, because - especially for innovations targeting at new markets, in particular at new industrial sectors - the required knowledge can only scarcely be covered by a single company. Thus, knowledge contributions of various partners are essential in order to effectively and efficiently transfer an initial idea to market success.

Knowledge required for innovation is likely to be obtained and distributed more easily within enterprise networks. Emerging technologies enable new dimensions of collaboration, regarding not only the agreement on common goals and the regular exchange of information, but also the conjoint performance of actions to realize innovation [Serrano, Fischer, 2007].

A systematic support for specific tasks of the innovation process can be offered by methods for innovation management. The application of these methods draws on available knowledge and can benefit from various viewpoints on a specific problem. Thus, the idea to apply these methods collaboratively with business partners seems obvious. However, this collaborative interenterprise application of innovation management methods has hardly been covered sufficiently by applied research up to now. This paper presents a novel approach how to use methods for innovation management in the collaborative setting of so-called Smart Networks and discusses how to systematically implement ICT tools supporting the execution of these methods. The findings are illustrated with an example from the European Community research project AVALON [AVALON, 2009], where the Failure Mode and Effects Analysis (FMEA) method has been applied in practice. 


\section{Collaborative Innovation in Smart Networks}

With the orientation along Organizational Networking, Knowledge Networking and ICT Networking [Filos, Banahan, 2001 and Filos, 2006] the conception of Smart Networks promises a high flexibility for collaboration. In this type of Virtual Organization, a new quality of collaboration is obtained through a dedicated integration of Knowledge Networking. Our research had the objective to create this new quality of collaboration along the knowledgeintensive processes of innovation.

For managing collaborative innovation the interaction between innovation process, innovation management methods and actors in the innovation process plays a significant role. Consequently, several key questions need to be answered that analyze their relation. Table 1 presents basic questions and how they relate to these aspects.

\begin{tabular}{|c|c|c|c|}
\hline & $\begin{array}{l}\text { Innovation } \\
\text { Process }\end{array}$ & $\begin{array}{l}\text { Innovation } \\
\text { Actors }\end{array}$ & $\begin{array}{l}\text { Innovation } \\
\text { Management } \\
\text { Methods }\end{array}$ \\
\hline $\begin{array}{l}\text { How does the innovation process look like? } \\
\text { (What do I have to do, and when shall I do it?) }\end{array}$ & $\mathbf{x}$ & & \\
\hline Which actors are involved? (Who can do it?) & & $\boldsymbol{\nabla}$ & \\
\hline $\begin{array}{l}\text { Which methods for innovation management are available? (How } \\
\text { can it be done?) }\end{array}$ & & & $\boldsymbol{x}$ \\
\hline $\begin{array}{l}\text { Which parts of the process can be supported with particular } \\
\text { methods? (How can I do what?) }\end{array}$ & 冈 & & 田 \\
\hline $\begin{array}{l}\text { Which parts of the process require the contributions of different } \\
\text { actors? (What to do with whom?) }\end{array}$ & 冈 & $\mathbf{x}$ & \\
\hline $\begin{array}{l}\text { Which actors should I involve for the application of a method? } \\
\text { (How to do with whom?) }\end{array}$ & & $\mathbf{x}$ & $\mathbf{x}$ \\
\hline
\end{tabular}

Table 1: Key questions analyzing collaborative innovation

The answers to these key questions must be provided (or developed) on basis of knowledge available in the network which could be termed Collaborative Innovation Knowledge. An ICT tool supporting the handling of the respective knowledge and information objects could be referred to as Collaborative Innovation Knowledge Repository (CIKR), which is outlined in Figure 1.

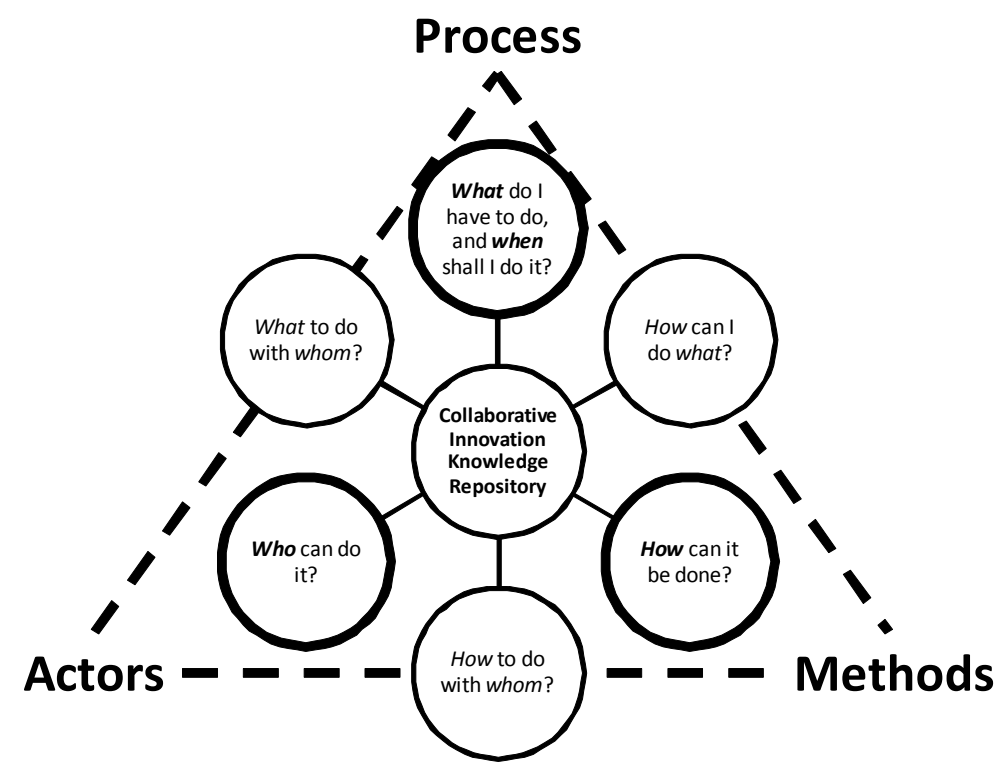

Figure 1: Collaborative Innovation Knowledge Repository 
The process of collaborative innovation is quite similar to an internal innovation process performed within a single company [see for instance Verworn, Herstatt, 2002, or Cooper, 2008]. However in networks, due to the major involvement of several independent actors, from a management perspective, a modular understanding of the innovation process seems to be preferable. An innovation process with a number of involved partners can then be separated into several parallel and complementary development projects, which need to be appropriately integrated. Some partial developments in this innovation scenario might be already well ahead while others are still in their early development phase. Moreover, backward steps and iterations have significant relevance for the process. Therefore the process of innovation can no longer be understood as being linear, passing one stage after another.

Internal and external actors can significantly contribute to the innovation process. To effectively integrate their contributions into the collaboration, it is essential to know which members of the network can represent which actors in the innovation process [Bellantuono et al., 2006]. In order to answer this question, extensive knowledge about the network's organizational aspects as well as available competences is required [Rehm, 2007]. Furthermore, it has to be clear which kind of activities in the innovation process can be supported by which kind of actors, and whether they are available as potential partners in the network or not.

The following paragraphs focus on the use of methods for innovation management. These methods offer a systematic support to different tasks in the innovation process. For using them collaboratively, it has to be defined at which stage they are to be applied in the innovation process and who of the actors is required for the proper application of the method.

\section{Collaborative Use of Methods for Innovation Management in Smart Networks}

Many methods for innovation management have been developed in the last decades. They have been subject to research and practical application, so that by now most of them are well understood for the application within a single company or a local team respectively. A detailed overview of appropriate methods can for instance be found in [Lindemann, 2006]. For the collaborative use of these methods by dispersed teams of actors, several aspects have to be considered which are outlined here.

In dispersed teams, in particular personal meetings of team members can not always be easily arranged. This limits the opportunity for brainstorming sessions or workshops while applying a method. Nevertheless, the proper knowledge exchange at such occasions might be crucial for the performance of the method. In order to enable this knowledge exchange, ICT tools can be used. The respective knowledge is then to be captured as information objects which can be exchanged through integrated ICT systems. Furthermore, due to the fact that team members belong to various companies, activities to be carried out in the innovation process need to be assigned to (functional) roles which clearly reflect the competences required to execute a particular task.

Many innovation management methods, especially those dealing with idea generation and development at the very beginning of the innovation process (the "fuzzy front-end of innovation" [Smith, Reinertsen, 1991]) leave quite some freedom in handling their implementation. They intend to encourage the creation of ideas and to avoid boundaries which are forcing a certain direction of thinking. Considering now that team members are not only locally dispersed but also use different terminology (corporate jargon) and adopt diverse viewpoints on the process (corporate perspective), this freedom might jeopardize the success of collaborative innovation. A better transparency of the inter-enterprise innovation process is required to enable the effective application of the method, directing the actors' contributions to where they are most valuable. These basic considerations about tool support for transparency and control of networking belong to the ICT Networking aspect in the Smart Networks conception.

Another critical aspect of collaborative innovation is trust which is required for encouraging the partners to exchange knowledge. Often not even obvious advantages of knowledge exchange can 
convince organizations to share their knowledge even within well-defined inter-enterprise collaborations. Thus, networking partners need to establish an understanding of the importance of knowledge exchange for the benefit of the entire network. This consideration belongs to the Knowledge Networking aspect in the Smart Networks conception. Confidentiality agreements in the network can offer some basic security here. Thereby, through a precise description of the structure and the process of the method, and through a clear identification of required knowledge inputs and outputs for each activity, the knowledge to be exchanged can be well-defined. Practical experiences in Smart Networks suggest that, as it becomes more transparent which knowledge is to give, and which knowledge to get (in principle), creating a trusted relationship becomes much easier.

The mentioned aspects of ICT Networking require a design for collaborative business processes which are specifically directed to the collaborative innovation process. Each innovation management method for collaborative innovation management needs to be adapted to the peculiar circumstances of the networking partnerships. This task belongs to the Organizational Networking aspect in the Smart Network conception.

In order to use a method for innovation management collaboratively, we suggest the following approach: The first step to be taken is a precise description of the structure and the modus operandi of the method, identifying and illustrating the different activities of the method. This can be performed by using a modeling tool which represents the principle procedure, e.g. by means of an event-driven process chain (EPC). Such a model will help to communicate the procedural method to all partners involved.

The identified activities need to be executed by people who are able to contribute the required knowledge. Therefore the next step is to model requirements for each activity in terms of knowledge input and output. On basis of these requirements, the responsibilities for each step can be derived with respect to roles.

The Smart Networks conception relies on ICT tools to support collaboration. The following chapter outlines how an innovation management method can be implemented as an ICT application.

\section{Implementation of Methods for Innovation Management as ICT Applications}

ICT applications supporting innovation management methods need to be based on the description of a method's structure and process. For that reason we have developed a systematic approach to implement an executable ICT application of an innovation management method on a collaboration platform. Our Model-driven Application Development (MAD) approach in principle follows the idea of the Object Management Group's (OMG) Model-driven Architecture (MDA) concept [see OMG, 2009]. Focusing on the development process for collaborative ICT applications, MAD suggests a modular development approach which explicitly allows for iterations, backward steps and cross-references between the various application development modules (see Figure 2). 


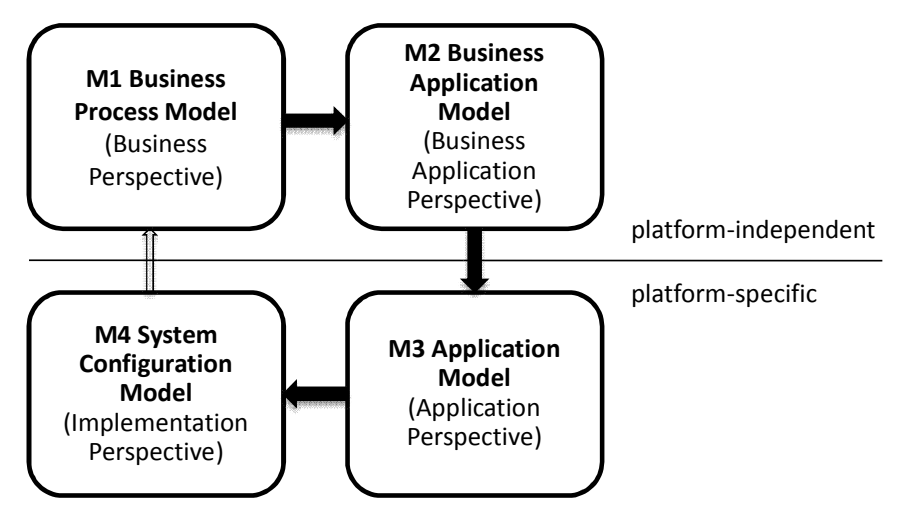

Figure 2: Model-driven Application Development (MAD) Approach

The MAD approach starts in a first module with structural and process models of the innovation management method to be applied (M1). In a second module, this business perspective is enriched with an ICT point of view (M2). The goal is to identify which parts of the process are to be supported by an ICT application as well as which users will employ which functionalities according to their specific roles. After that, the developers are ready to decide on the ICT platform on which to realize the application.

Various platforms available will also ask for different meta-models for the following steps of platform-specific modeling. The first platform-specific module comprises models describing the components provided by the application and how these components can interact (M3). Finally, models for platform configuration are developed (M4). In contrast to the OMG's MDA, this module does not target at creation of software code, but to create a service-oriented model of the implementation. It has to be mentioned that this module covers also executable models of ICT applications, e.g. system configurations which are interpreted by a platform engine.

In this context, several specific features of collaborative ICT applications need to be respected. It has to be considered for example that relevant information and explicit knowledge which may be necessary for application of the respective method may be already available, but may reside in distributed systems. The ICT application to be designed needs to be capable of utilizing this information. The MAD approach therefore explicitly allows modeling the connections to distributed systems. A further issue is the integration of the application to be developed with applications already existing. Patterns for Enterprise Architecture Management as described in [Lau et al., 2009] can support this step.

\section{Practical Example: Implementation of the Failure Mode and Effects Analysis}

Within the European Community research project AVALON, several Smart Networks were established. Their members have collaboratively performed the innovation process from product idea to prototype. Members of these Smart Networks are locally dispersed, therefore their innovation activities have been supported by a collaboration platform. Several methods for innovation management have been applied in this setting, which helped the partners to systematically tackle specific aspects of the innovation process. One of these methods was the Failure Mode and Effects Analysis (FMEA) methodology which is taken as an example for illustration of the method implementation in this paper.

The FMEA is a renowned and widely used method for innovation and risk management. It supports the systematic identification, prioritization and reduction of product and process risks [US Department of Defense, 1980]. Although often applied on already existing products and processes, it is also very well suited to be used in early stages of the development of a new product, e.g. to evaluate the product concept [Dahmen, 2002]. Analyzing not only possible risks, but also possible causes and imaginable effects of these risks, the method can benefit strongly from external knowledge contributions. Suppliers for instance may have a deep insight in 
specific causes for failure related to their materials while customers can contribute effects of the risks that they have experienced in using this or similar materials.

To enable application of the FMEA in Smart Networks, the Model-driven Application Development (MAD) approach was applied. First, the methodological approach has been analyzed and modeled. Using the concept of business process modeling, the focus of this analysis has been to identify necessary activities together with the corresponding responsibilities. This has been performed independently of organizational hierarchies, focusing only on roles executing these activities.

In a further step, also ICT and knowledge aspects have been considered. The detailed analysis of necessary exchange of information and knowledge is a prerequisite for a comprehensive implementation of the method as ICT application. Consequently, the focus of this analysis has not only been on information and knowledge repositories and on information and knowledge relevant for certain activities. Also the different forms of knowledge transformations as they are described by Nonaka and Takeuchi [Nonaka, Takeuchi, 1995] were identified. The following Figure 3 shows exemplarily the activities necessary for the identification of risks. The lower part of the model contains also socialization and externalization activities as knowledge transformations.

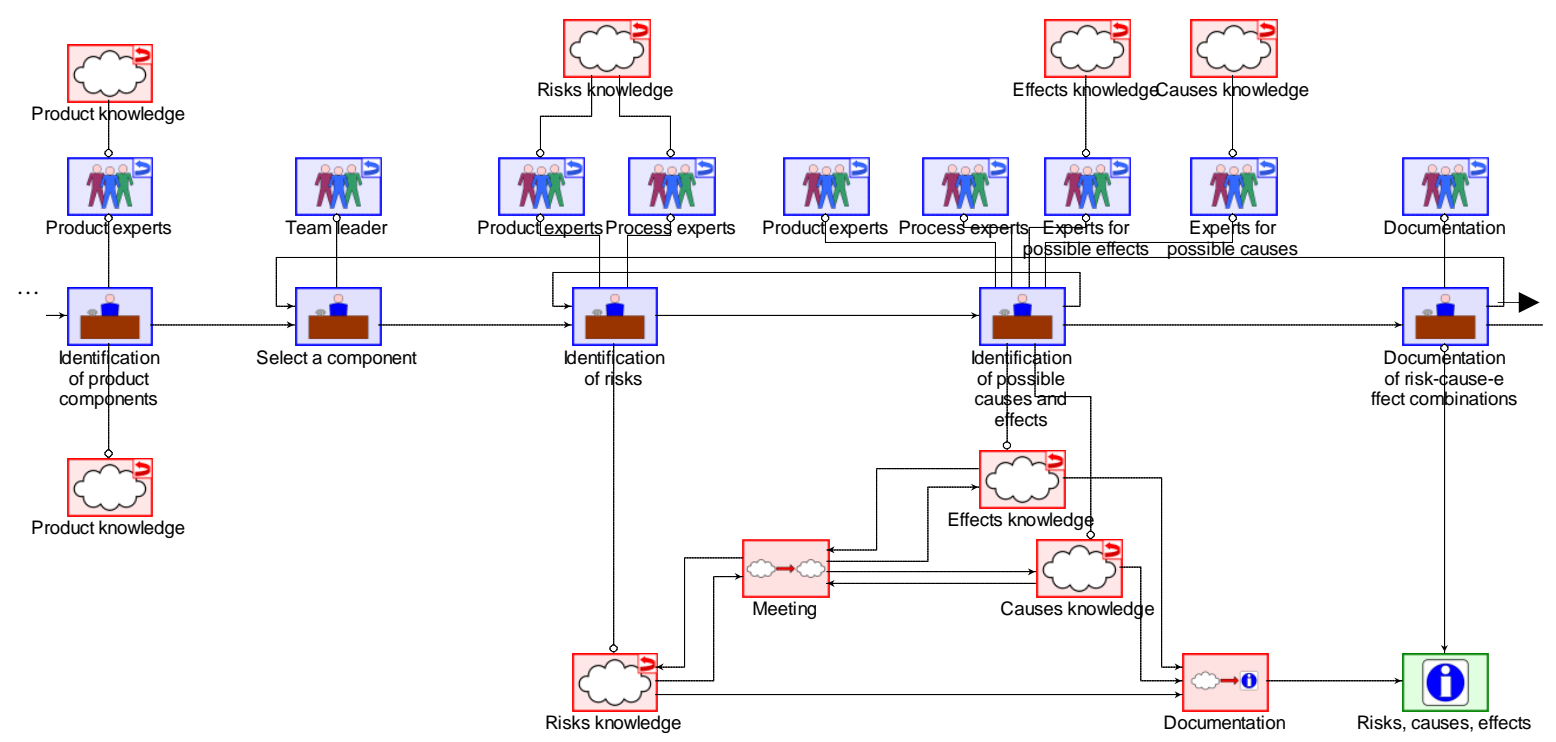

Figure 3: Excerpt of the FMEA process model with included knowledge transformations

Having modeled the business perspective, the MAD approach suggests the identification of possible support of the process through additional ICT applications. Accordingly, the business process models have been supplemented with additional information about activities relevant for the development of a collaborative FMEA application.

Next step in application development is the creation of platform-specific models. For the AVALON project the Service-Oriented Architecture (SOA) integration platform efikton ${ }^{\circledR}$ [Diasfalisis, 2009] has been selected for implementation of the collaborative innovation management methods. A specific modeling language has been developed using the Generic Modeling Environment (GME) which provides a modeling environment to create domainspecific meta-models [University of Vanderbilt, 2008]. Using these meta-models to create platform-specific models of the application allowed implementing the applications on the platform. Part of the final application is illustrated in Figure 4. It shows a screenshot from the FMEA application, displaying several data sets with information on risks (section (1)), as well as individualized buttons for the start of activities during the work flow sequence of the method (2). 


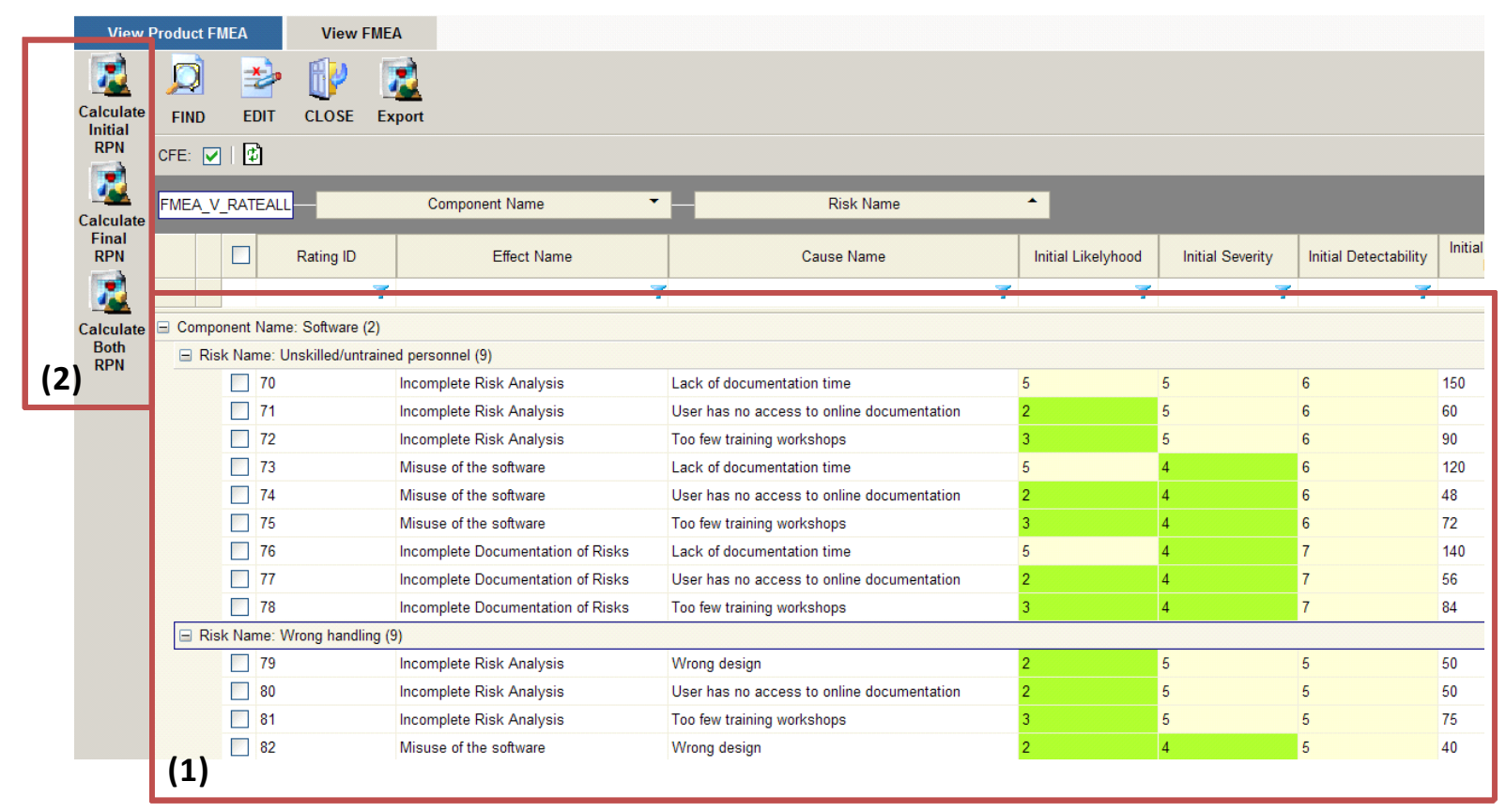

Figure 4: Screenshot of the FMEA application on the collaboration platform efikton ${ }^{\circledR}$

\section{Findings and Conclusions}

The concepts and methods which are presented in this paper have been developed and applied in the scope of the European Community research project AVALON. The objective of this project has been to establish innovation networks for the cross-sectoral development of products and services, comprising partners from textile, automotive, aerospace and further industrial sectors. During the project several Smart Networks were established. To support the innovation processes within these networks, a collaboration platform was implemented which provides various ICT applications. This platform additionally provides an application development environment. Innovation management methods have been selected, modified and implemented on this platform according to the MAD approach described above.

Practical experiences concerning the implementation of the presented approach suggest that methods for innovation management can substantially support collaborative innovation, although in some cases an adaptation of the process regarding its collaborative application was necessary. In order to develop an ICT application for such a method, the MAD approach has proven valuable as it systematically guides the development by its four modules, ranging from models of the general business process to specific implementation models of the application.

Future research will focus on transferring further innovation management methods into collaborative ICT applications. Aim is to improve the understanding of how the structure and the process of methods influence the capabilities of collaborative innovation. This will in turn help to refine the MAD approach, and especially the transitions between the different modules. Further research activities currently extend this approach by combination with semantic services which are expected to be of significant relevance in this field.

\section{Acknowledgement}

The work presented in this paper has been carried out in the context of the AVALON project (No. NMP2-2005515813-2, http://www.avalon-eu.org) co-funded by the European Commission under the $6^{\text {th }}$ Framework Program. The authors would like to acknowledge the support of the European Commission and the comments and contributions of the AVALON project partners. 


\section{References}

AVALON (2009) Multifunctional textile structures driving new production and organizational paradigms by textile SME interoperation Across high-added-VALue sectOrs for knowledge-based product/service creatioN (AVALON). Integrated Project for SMEs, European Commission Community Research $6^{\text {th }}$ Framework Programme, Priority 3 NMP (NMP2-T-2005-515813-2). Obtained through the Internet: http://www.avaloneu.org, accessed 15.04.2009.

Bellantuono, N., Pontrandolfo, P., Scozzi, B. (2006) Knowledge networks within supply chain to foster innovation. In: Proceedings of the 14th International Working Seminar on Production Economics. Innsbruck, Austria, February 20-24, 2006.

Cooper, R. (2008) Perspective: The Stage-Gate Idea-to-Launch Process - Update, What's New and NexGen Systems. Journal of Product Innovation Management, Vol. 25, 2008, p. 213-232.

Dahmen, J. (2002) Prozeßorientiertes Risikomanagement zur Handhabung von Produktrisiken. Shaker, Aachen, 2002.

Diasfalisis (2009) Efikton ${ }^{\circledR}$ Platform. Obtained through the Internet: http://www.diasfalisis.com/efikton, accessed 01.04.2009.

Filos, E., Banahan, E. (2001) Will the Organisation Disappear? The Challenges of the New Economy and Future Perspectives, In: Camarinha-Matos, L.M., Afsarmanesh, H., Rabelo, R. (Eds.): E-Business \& Virtual Enterprises. Dordrecht, 2001, pp. 2-30.

Filos, E. (2006) Smart Organizations in the Digital Age, In: Mezgár, I. (Ed.): Integration of Information and Communication Technologies in Smart Organizations. Idea Group Publishing, Hershey, 2006, pp. 1-38.

Lau, A., Fischer, T., Weiß, M., Buckl, S., Ernst, A., Matthes, F., Schweda, C. (2009) EA Management Patterns for Smart Networks, In: Software Engineering 2009 Workshopband. Kaiserslautern, Germany, March 2-6, 2009. Proceedings to be published 2009.

Lindemann, U. (2006) Methodische Entwicklung technischer Produkte. Methoden flexibel und situationsgerecht anwenden. Berlin, Heidelberg, New York, Springer, 2006.

Nonaka, I., Takeuchi, H. (1995) The Knowledge-Creating Company: How Japanese Companies Create The Dynamics of Innovation. University Press, Oxford, 1995.

OMG (2009) OMG Model Driven Architecture. Obtained through the Internet: http://www.omg.org/mda, accessed 28.01.2009.

Rehm, S.-V. (2007) Architektur vernetzter Wertschöpfungsgemeinschaften der Textilwirtschaft. (Architecture of Networked Value Added Communities of Textile Industries). Dissertation, University of Stuttgart, Online Publication, http://elib.uni-stuttgart.de/opus/volltexte/2007/3197/, accessed 12.03.2009.

Serrano, V., Fischer, T. (2007) Collaborative Innovation in Ubiquitous Systems. Journal of Intelligent Manufacturing, Vol. 18, Oct. 2007, p. 599-615.

Smith, P.G., Reinertsen, D. (1991) Developing Products in Half the Time. Van Nostrand Reinhold, New York, 1991.

University of Vanderbilt (2008) GME: Generic Modeling Environment. Obtained through the Internet: http://www.isis.vanderbilt.edu/projects/gme/, accessed 16.02.2009.

US Department of Defense (1980) MIL-STD-1629A: Procedures for Performing a Failure Mode, Effects and Criticality Analysis. Obtained through the Internet: http://www.goesr.gov/procurement/ground_documents/ Reference\%20Documents/MIL-STD-1629A.pdf, accessed 12.01.2009.

Verworn, B., Herstatt, C. (2002) The innovation process: an introduction to process models. Working Paper No. 12, TU Harburg, 2002. Obtained through the Internet: http://www.tu-harburg.de/tim/downloads/arbeitspapiere/ Working_Paper_12.pdf, accessed 25.05.2008. 